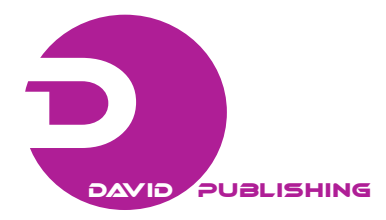

\title{
Spatial Quality Evaluation of Pedestrian Streets
}

\author{
Renata Cardoso Magagnin, Maria Solange Gurgel de Castro Fontes and Rosio Fernandez Baca Salcedo \\ Architecture, Arts and Communication Faculty, UNESP_Univ Estadual Paulista, Bauru 17033-360, Brazil
}

\begin{abstract}
This paper presents an assessment of the spatial quality of a pedestrian street located in downtown Bauru, São Paulo State, Brazil, from the application of some urban sustainability indicators. Multi-method was used to evaluate the thermal comfort quality of users, urban accessibility and preservation of architectural heritage. The results show that the sustainability indicators, apart from being effective tools in identifying problems, can assist local managers in decision making, planning and monitoring of pedestrian public space. These indicators contribute to a broad diagnosis of the pedestrian street and also the formulation of programs, projects and municipal policies, aimed at providing a better life quality for pedestrians.
\end{abstract}

Key words: Pedestrian street, sustainability, sustainability indicators.

\section{Introduction}

In recent decades, urban experts and decision-makers have incorporated the theme of "sustainability" in discussions about urban development due to spatial degradation and decrease of life quality experienced in cities. In Brazil, this issue gained prominence since the United Nations Conference on Environment and Development, held in Rio de Janeiro in 1992, known as Rio 92 [1].

From this new concept, a set of indicators was created to measure the degree of sustainability of a country, state or city, incorporating the environmental, economic and social areas, and covering different evaluation levels and/or evaluation environments: the built environment and infrastructure; buildings and materials, among others [2].

The indicators can be considered planning instruments, because they were created with the purpose of assisting in the choice of policy alternatives, indicating the goal and direction for decision making.

In the urban environment, sustainability indicators can subsidize actions to be implemented by local administrators, in the recovery of degraded areas,

Corresponding author: Renata Cardoso Magagnin, Ph.D., professor, research fields: urbanism, urban mobility and urban accessibility.E-mail: magagnin@faac.unesp.br. revitalization of central areas and/or implementation of new projects in order to contribute to urban vitality and, hence, improve the quality of life in cities. For revitalizing, downtown areas should be considered the building preservation and its near context, it is therefore the urban network and buildings constituting an identity that must be preserved [3].

There is still great difficulty in assessing the potential of urban space, from an instrument that can incorporate different areas of knowledge [1]. Authors such as Romero [4], Lopes [2] and Huang et al. [1] have developed studies of urban sustainability indicators that can be used to assess the quality of the built environment.

In Brazil, Romero [4] shows that public space can be analyzed by incorporating the following indicators: comfort in outdoor spaces and buildings, accessibility, the mobility and accessibility of vehicles, segregation, urban complexity, energy efficiency, hydraulic efficiency and edification efficiency.

On the other hand, Lopes [2] extends this analysis showing other aspects, which include, among other things, issues related to natural ecosystems, energy, water, materials, air emissions, noise, landscape and heritage (protection and enhancement of heritage).

In this context, this paper seeks to contribute to a system of indicators which allows to evaluate the 
spatial quality of pedestrian streets, using different methods.

These indicators were used in a case study on a pedestrian street located in the central area of the city of Bauru, in the São Paulo State, Brazil, to evaluate the quality of the thermal comfort of users, urban accessibility and preservation of architectural heritage.

\section{Study Area}

The pedestrian street analyzed is known as "Calçadão" of Batista de Carvalho Street. It is located in the central area of Bauru (latitude $22^{\circ} 35^{\prime} \mathrm{S}$ and longitude $49^{\circ} 31^{\prime} \mathrm{W}$ ), medium-sized city located in the center west region of São Paulo (Figs. 1 and 2).

Its climate is Aw type, according to Koeppen climate classification for the São Paulo State, where the climate is tropical with dry winter of average temperature of over $18{ }^{\circ} \mathrm{C}$. The city has a population of approximately 344,000 inhabitants, distributed in an area of $668 \mathrm{~km}^{2}$ [5].

In general, the pedestrian streets are treated spatially with specific equipment and furniture in order to ensure greater convenience and comfort to users, as is the case of the analyzed street, which has

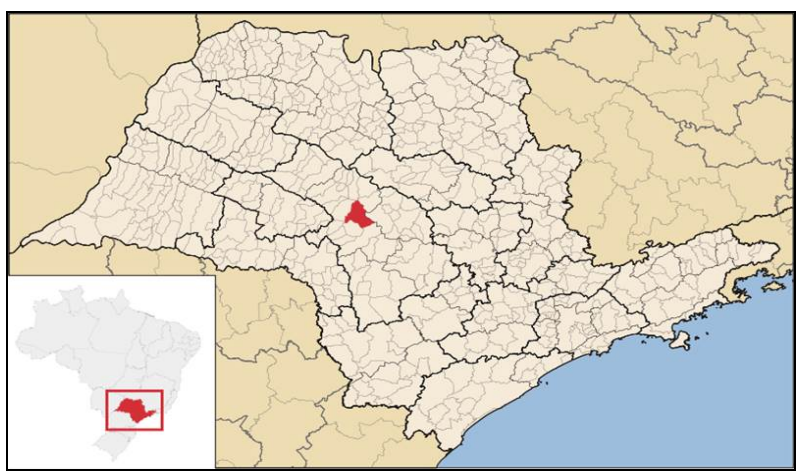

Fig. 1 Location of Bauru in São Paulo State, Brazil.

Source: Bauru, 2014. Available in: http://www.bauru.sp.gov.br/ cidade/dados_geograficos.aspx.
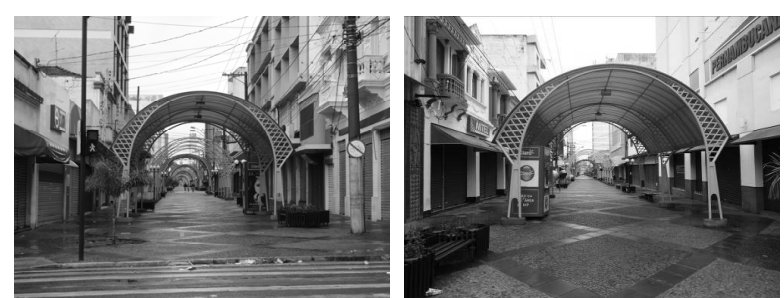

Fig. 2 Pictures of the area under study. the following characteristics: Portuguese stone and concrete slab as pavement; gantries of metal framework, some of which have coverage of polycarbonate; benches, planters, payphones, mailboxes, trash cans and lampposts.

Regarding the commercial and service buildings along the street, the Art Deco and Eclectic architectural style ones are highlighted, and three of them are listed by the Defense Council of Cultural Heritage site.

\section{Materials and Methods}

The formulation of urban sustainability indicators to assess the spatial quality of a pedestrian street had the studies carried out by Romero [4], Lopes [2], Huang et al. [1], Queiros and Portela [6], Blanco [3] and Salcedo [7] as reference. Thus, indicators related to the quality of thermal comfort (microclimate), quality of urban accessibility (pedestrian accessibility) and quality of patrimony (preservation of architectural heritage) were adopted.

To this end, qualitative and quantitative methods and techniques were used to collect and analyze the data through the application of questionnaires to users, microclimate monitoring, photographic survey of urban space and facades, survey of buildings declared as public heritage and consultation of the guidelines made by the CODEPAC (Defense Council of Bauru Cultural Heritage). The methods and techniques used to evaluate each indicator are described below.

\subsection{Microclimate}

The research on thermal comfort conditions in the pedestrian street was held in different weather conditions (cold and hot) and was based on the research conducted by Faustini and Fontes [8]. This research includes monitoring the microclimate (air temperature, air humidity, global solar radiation and air velocity) and questionnaires to identify the thermal sensation and satisfaction of users with the space.

A mobile meteorological station with sensors for air 
temperature, relative humidity, air velocity and solar radiation was used to monitor the microclimate variables. The microclimate monitoring was performed in two days in September 2008 and three days in March 2009, during the morning ( 9 am to $12 \mathrm{pm}$ ) and afternoon ( $2 \mathrm{pm}$ to $5 \mathrm{pm}$ ) in three different blocks of streets (1, 3 and 5) with different usage characteristics, occupation and FVS (sky view factors).

These data allowed to calculate the thermal comfort condition through PET (physiological equivalent temperature) index, introduced by Mayer and Höppe [9] using the software RayMan [10], and evaluate the percentage of people feeling comfortable in both periods considering the range of $18 \sim 26{ }^{\circ} \mathrm{C}$ thermal neutrality, according to studies carried out in pedestrian public spaces in cities in São Paulo State [11]. A scale was adopted to quantify the sustainability indicator in microclimatic aspect: from very bad to excellent ( $0 \% \sim 20 \%$, very bad; $21 \% \sim 40 \%$ bad; $41 \% \sim 60 \%$ regular; $61 \% \sim 80 \%$, good; $81 \% \sim 100 \%$, excellent), regarding the percentage of people comfortable in cold and hot weather conditions.

\subsection{Accessibility}

The urban accessibility was evaluated by indicators proposed by Fruim [12], Ferreira and Sanches [13], Magagnin et al. [14], Sarkar [15], which enabled the assessment and monitoring of the infrastructure for pedestrians through three themes: (1) comfort quality; (2) security quality; (3) environmental quality. Data collection involved field work (by conducting on-site observations, measurements and photographic survey) and questionnaires for the users.

The questionnaires used in this research were developed and tested in 2008 and, for this reason, a pilot test was not conducted. The questions consisted of open and closed answers (multiple choices) that allowed to identify the user profile and evaluate the accessibility of the site by the road infrastructure available under the viewpoint of the user responses, both qualitatively and quantitatively. The photographic records were also used and allowed to identify the accessibility issues highlighted in the questionnaires.

A sample of 85 people of different age groups participated in this evaluation. The method of multi-criteria analysis was adopted and the 5-point rating scale was chosen because it could be easily understood by the target audience of the research. The scale is composed of the following values: 1 (very bad), 2 (bad), 3 (regular), 4 (good) and 5 (excellent).

The analysis was performed using the ranking of indicators by level of importance and themes (comfort quality, security quality and environmental quality). Initially, the average weights of each criterion were calculated by reviewer. Subsequently, the mean values of each weight were calculated by indicators and their respective rankings were set.

\subsection{Preservation of Architectural Heritage}

The analysis of the degree of preservation of architectural heritage was based on the Decrees of Tipping issued by CODEPAC [16] and comparison of the building original facades with the current ones. A scale of values was assigned for this analysis: excellent, when the property was restored according to the its original features; good, when the property is preserved with its original features; regular, when the original color of the facade was changed in the intervention of the property; bad, when the property was undergone interventions that partially mischaracterized it (expansion of doors, windows, etc.) but can still be restored to recover its original features; and very bad, when the building was completely mischaracterized [17].

As elements of analysis of the architectural heritage ambience, the following aspects were considered: height gauges, elements and material of finishes of the facades and street furniture (materials used in finishing).

\section{Results and Discussion}

The analysis of the results concerning the 
application of urban sustainability indicators on Batista de Carvalho Street is presented in the following order: microclimate, urban accessibility and historic preservation.

\subsection{Microclimate Analysis}

The analysis of the conditions for thermal comfort on the pedestrian street "Batista de Carvalho", in hot and cold weather, showed significant differences in both periods. In cold weather (two days in September 2008), the microclimatic conditions showed low temperatures in the morning and high temperatures in the afternoon, with average temperatures ranging from $18.6^{\circ} \mathrm{C}$ (morning) to $25.1^{\circ} \mathrm{C}$ (afternoon). The relative humidity showed higher values during the mornings $(55.35 \%)$ than in the periods of the afternoon. During three days of March 2009, the days were characterized by hot and humid weather $\left(27.9{ }^{\circ} \mathrm{C}\right.$ and $\left.63 \%\right)$ in the mornings, and hot and dry in the afternoon $\left(30.7^{\circ} \mathrm{C}\right.$ and $44.5 \%$ ).

The calculation of the comfort PET index for the first observation period (September 2008) revealed a higher percentage of people feeling comfortable, around $70 \% \sim 80 \%$ of people interviewed. In this period, the causes of discomfort were the low temperatures and cold winds in the morning. However, the analysis of the PET index in the second period (during the month of March 2009) showed a thermal discomfort in $100 \%$ of users. The thermal dissatisfaction was attributed to high temperatures during the day and low relative humidity observed especially in the afternoon.

These results allow the evaluation of the sustainability indicators of the area in relation to thermal comfort conditions in both periods. In the first period, the evaluation was good, since a range of $71 \% \sim 80 \%$ of comfortable persons was observed. In the second case, the assessment was very bad (0\% 20\%), which highlights the need for a project-intervention, with the aim of reducing the high temperatures in summer and humidifying the air during the afternoons in both periods.

\subsection{Urban Accessibility Analysis}

The analysis of urban accessibility identified the main problems related to the quality of the infrastructure for pedestrians (comfort, safety and the environment) in this public space (Table 1).

In the analysis of the partial rank column, the cells in light gray show the most important problems being considered by theme evaluated and the scale adopted by relevance order of the indicator.

On the theme comfort quality, it was identified that the major problems in this space were related to the presence of steps in access to commercial establishments, with high density of pedestrians (especially on Saturdays and near holidays) and loose flooring, consisting of Portuguese stones that hinder walking.

When analyzing the data relating to the theme of security quality, a fact that stands out is the absence of ramps (constructed in accordance with technical standards) and their proper conservation, which allows free access to all blocks of this street. Another finding was the bad visibility when crossing the streets to access other blocks of the pedestrian street. In some places, there is no visibility of the vehicles coming and that can endanger a safe crossing.

Regarding the environment quality, the survey showed the following deficiencies: lack of shading areas (of buildings, marquees or trees) and lack of adequate illumination at night, which compromise the security to users. In the first case, as the city has a very hot climate, the lack of shading causes a lot of discomfort to users.

The analysis of the total ranking emphasizes that the most important indicators (the first five positions, which represent the biggest problems) for users of the pedestrian street, belonged to the theme environmental quality (related to sun light, illumination, trees, noise and air pollution) followed by the theme security quality and comfort quality. 
Table 1 Ranking of the major accessibility problems found on pedestrian street.

\begin{tabular}{|c|c|c|c|c|c|}
\hline \multicolumn{3}{|l|}{ Theme } & Weight & Partial ranking & Total ranking \\
\hline \multirow{9}{*}{ Comfort quality } & \multicolumn{2}{|c|}{ Effective width } & 0.0528 & 9 & 23 \\
\hline & \multicolumn{2}{|c|}{ State conservation of the pavement-maintenance } & 0.0487 & 8 & 18 \\
\hline & \multicolumn{2}{|c|}{ Characteristics of the material used on road surfacing } & 0.0439 & 4 & 13 \\
\hline & \multicolumn{2}{|c|}{ Ground discontinuous } & 0.0471 & 6 & 16 \\
\hline & \multicolumn{2}{|c|}{ Ground broken sidewalks } & 0.0433 & 3 & 12 \\
\hline & \multicolumn{2}{|c|}{ Different levels } & 0.0471 & 7 & 17 \\
\hline & \multicolumn{2}{|c|}{ Sidewalks blocked by urban furniture } & 0.0447 & 5 & 14 \\
\hline & \multicolumn{2}{|c|}{ Pedestrian density } & 0.0409 & 2 & 8 \\
\hline & \multicolumn{2}{|c|}{ Existence of steps } & 0.0399 & 1 & 7 \\
\hline \multirow{7}{*}{ Comfort security } & \multicolumn{2}{|c|}{ Horizontal signs } & 0.0527 & 7 & 22 \\
\hline & \multicolumn{2}{|c|}{ Pedestrian traffic lights } & 0.0525 & 6 & 21 \\
\hline & \multicolumn{2}{|c|}{ Lack of ramps (access to the blocks) } & 0.0411 & 2 & 9 \\
\hline & \multicolumn{2}{|c|}{ Ramps for disabled-conservation } & 0.0394 & 1 & 6 \\
\hline & \multicolumn{2}{|c|}{ Traffic lights time } & 0.0509 & 5 & 20 \\
\hline & \multicolumn{2}{|c|}{ Deficient signs } & 0.0428 & 4 & 11 \\
\hline & \multicolumn{2}{|c|}{ View of approaching vehicles when crossing } & 0.0427 & 3 & 10 \\
\hline \multirow{7}{*}{ Environment quality } & \multicolumn{2}{|c|}{ Urban forestry } & 0.0364 & 3 & 3 \\
\hline & \multicolumn{2}{|c|}{ Insulation } & 0.0272 & 1 & 1 \\
\hline & \multicolumn{2}{|l|}{ Lighting } & 0.0329 & 2 & 2 \\
\hline & \multicolumn{2}{|c|}{ Urban furniture } & 0.0467 & 6 & 15 \\
\hline & \multirow{2}{*}{ Pollution } & Noise & 0.0381 & 4 & 4 \\
\hline & & Air & 0.0387 & 5 & 5 \\
\hline & \multicolumn{2}{|c|}{ Aesthetics } & 0.0495 & 7 & 19 \\
\hline
\end{tabular}

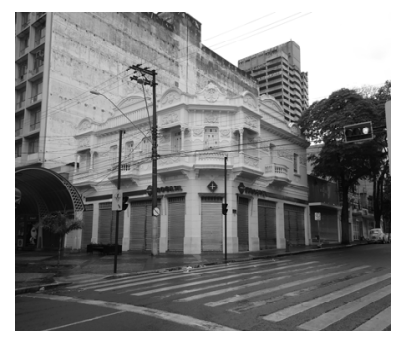

(a)

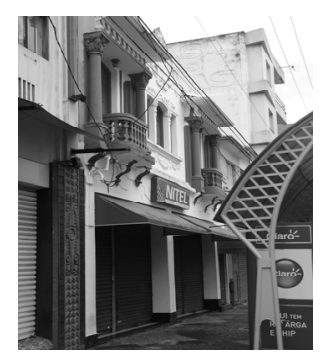

(b)

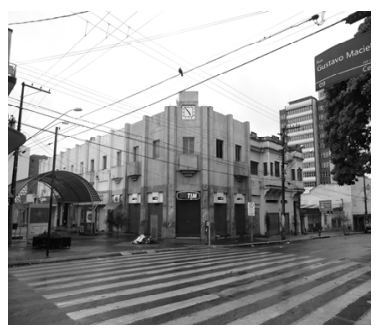

(c)

Fig. 3 Buildings listed by CODEPAC: (a) Palace Pagani; (b) Older Commercial House; (c) Lusitana House.

According to the data presented in the questionnaire, it was possible to calculate the rate of urban accessibility for this space. This index was performed by calculating the mean values assigned to each user for 23 indicators.

The results indicated that $9 \%$ of respondents consider the space with bad accessibility, $29 \%$ think the place has good accessibility and $61 \%$ consider it inaccessible (or with regular access). These data show that, for this site to be considered sustainable in terms of accessibility, it is necessary that the municipality adopts some urban interventions, aimed at solving the problems identified in Table 1, adopting measures in the short, medium and long terms.

\subsection{Preservation of Architectural Heritage Analysis}

The pedestrian street consists of several buildings dating from the early 20th century in Art-Deco and Eclectic style. However, only three buildings were listed by the board of preservation of local heritage (CODEPAC): Lusitana House, Older Commercial House and Pagani Palace (Fig. 3). 
Table 2 Conservation state of building protection and their ambience.

\begin{tabular}{|l|l|l|l|l|l|}
\hline \multirow{2}{*}{ Protection building } & \multicolumn{5}{|c|}{ Conservation state } \\
\cline { 2 - 6 } & Excellent & Good & Regular & Bad & Very bad \\
\hline Lusitana House & & & & & \\
\hline Older Commercial House & & & & & \\
\hline Pagani Palace & & & & & \\
\hline Building ambience & & & & & \\
\hline
\end{tabular}

Table 3 Level of urban sustainability.

\begin{tabular}{|l|l|l|l|l|l|l|}
\hline \multirow{2}{*}{ Indicator } & \multicolumn{5}{|c|}{ Level of sustainability } \\
\cline { 3 - 7 } & Excellent & Good & Regular & Bad & Very bad \\
\hline Microclimate & & & & & \\
\hline Urban accessibility & Summer & & & & & \\
\hline Preservation of architectural heritage & & & & & \\
\hline
\end{tabular}

In general, the act of declaring the existing buildings on Batista de Carvalho Street as public heritage aims at the preservation of their facades, with their component elements (ornamental, window frames and finishing materials) and their volume.

Lusitana House and Older Commercial House suffered interventions on the facades. The former had its original color changed and the latter suffered alterations that mischaracterized the original building, such as enlargement of the doors at the ground floor of the facade and change of its original color. The Pagani House was restored keeping its original features, therefore, its conservation status is good (Table 2).

Regarding the analysis of the area of ambience, the conservation status of the buildings is classified as regular and bad. To accommodate trade and services on the ground floor, these buildings have suffered mischaracterization of facade (opening of new doors and broadening the existing ones, installation of commercial signage which pollutes the facades, etc.) and change of the original color.

These factors contribute to the loss of historical and architectural values. Therefore, to improve the quality of the built environment of the pedestrian street "Batista de Carvalho" is necessary to restore the facades recovering its original features and replace the commercial advertisements by smaller ones, becoming part of the composition of the building and not causing visual pollution.

\subsection{Spatial Quality}

To evaluate the spatial quality of this pedestrian street and set its level of urban sustainability, the same scale of values (very bad to excellent) used in the individual analysis (by indicator) was adopted.

According to the results obtained with the application of the three indicators, it can be stated that Batista de Carvalho Street has a regular level of sustainability (Table 3). To achieve a better performance, it is necessary that local urban managers implement measures to minimize the problems of high temperatures during the summer, the questions about the accessibility of users and the restoration and preservation of buildings.

\section{Conclusions}

The application of urban sustainability indicators for the evaluation of pedestrian streets allowed the identification of several urban problems related to microclimatic, aspects of urban accessibility and maintenance, preservation of the public space and buildings that are interfering with spatial quality, attractiveness and permanence of users.

In order to widen the level of sustainability in these aspects, there is a need for: (1) protection from direct 
solar radiation to improve thermal comfort conditions for pedestrians; (2) implement interventions to improve spatial accessibility based on the accessibility of Brazilian Technical Standard (NBR 9050); (3) regulate the process of restoring the facades allowing reconstitution of its original features and their ambiences.

Considering these results, it can be stated that the proposed indicators are intended to contribute to similar analyzes, contributing to: (1) composing a system of urban sustainability indicators, which can assist local managers in decision making, planning and monitoring of pedestrian public space; (2) the achievement of a broad analysis of the pedestrian street, in order to propose guidelines that, at short and medium term, can be implemented, and thus, make the space more sustainable; (3) the formulation of programs, projects and municipal policies, aimed at providing a better quality of life for pedestrians.

For the future, researches recommend expanding the urban sustainability indicators to evaluate the other parameters that affect the spatial quality of pedestrian space, such as: visual and acoustic comfort, aesthetics aspects, urban equipments among others.

\section{Acknowledgments}

The authors would like to express their gratitude to the Brazilian agencies FAPESP (Foundation for the Promotion of Science of the State of São Paulo) and PROPe (Dean of Research of UNESP), FUNDUNESP (Foundation for Development of UNESP), which have supported their efforts for the development of this work in different ways and periods.

\section{References}

[1] S.L. Huang, J.H. Wong, T.C. Chen, A framework of indicator system for measuring Taipei's urban sustainability, Landscape and Urban Planning 42 (1998) 15-27.

[2] A.K.G. Lopes, Urban regeneration: Assessment by sustainability indicators, Master's Thesis, Aveiro University, Portugal, 2010. (in Portuguese)

[3] J.R. Blanco, De Varia Restauracione. Teoria e Historia de la Restauración (From Various Restauracione, Theory and History of Restoration), Abada Editores, Madrid, Espanha, 2008. (in Spanish)

[4] M.A.B. Romero, Frentes do urbano para a construção de indicadores de sustentabilidade intra-urbana. (Urban's fronts for the construction of indicators of intra-urban sustainability), Paranoá: Cadernos de Arquitetura e Urbanismo (Books of Architecture and Urbanism) 6 (4) (2007) 47-62. (in Portuguese)

[5] Instituto Brasileiro de Geografia e Estatística (Brazilian Institute of Geography and Statistics), Censuss, 2010 [Online], http://www.ibge.gov.br/ (accessed Apr. 1, 2014). (in Portuguese)

[6] J.F. Queiros, A.M. Portela, Conservação Urbana e Territorial Integrada. Reflexões Sobre Salvaguarda, Reabilitação e Gestão em Centros Históricos em Portugal (Urban Conservation and Integrated Territorial. Reflections on Safeguarding, Rehabilitation and Management of Historical Centers in Portugal), Livros Horizonte Ltda, Lisboa, Portugal, 2009. (in Portuguese)

[7] R.F.B. Salcedo, A reabilitação das Residências nos Centros Históricos da América Latina: Cusco (Peru) e Ouro Preto (Brasil) (The Rehabilitation of the Homes in the Historic Centers of Latin America: Cusco (Peru) and Ouro Preto (Brazil)), Editora UNESP. São Paulo, Brasil, 2007. (in Portuguese)

[8] F.B. Faustini, M.S.G.C. Fontes, Conforto térmico em espaços públicos de passagem: Estudos no calçadão da Batista de Carvalho em Bauru-SP, Brasil (Thermal comfort in pedestrian street: Studies in the Batista de Carvalho street in Bauru-SP), in: Proceedings of 4th Luso Brazilian Congress on Urban, Regional, Integrated Sustainability Planning, 2010, pp. 1-12. (in Portuguese)

[9] H. Mayer, P. Höppe, Thermal comfort of man in different urban environments, Theoretical and Applied Climatology 38 (1987) 43-49.

[10] A. Matzarakis, F. Rutz, H. Mayer, Modelling radiation fluxes in simple and complex environments: Application of the RayMan model, International Journal of Biometeorology 51 (2007) 323-334.

[11] L.C. Labaki, M.S.G.C. Fontes, C.L. Bueno-Bartolomei, C Dacanal, Conforto térmico em espaços públicos de passagem: Estudos em ruas de pedestres no Estado de São Paulo (Thermal comfort in public spaces: Studies in pedestrian streets in São Paulo State), Ambiente Construído [Online], 167-183, http://www.scielo.br/pdf/ ac/v12n1/v12n1a03.pdf (accessed Dec. 1, 2012). (in Portuguese)

[12] J.J. Fruim, Pedestrian Planning and Design, Metropolitan Association of Urban Designers, New York, USA, 1987.

[13] M.A.G. Ferreira, S.P. Sanches, Proposal of a sidewalk 
accessibility index, Journal of Urban and Environmental Engineering 1(1) (2007) 1-9.

[14] R.C. Magagnin, R.F.B. Salcedo, M.S.G.C. Fontes, Urban sustainability in pedestrian street in downtown areas: Case study of Bauru-Brazil, in: Proceedings of PLEA 2012 - 28th Conference, Opportunities, Limits \& Needs towards an Environmentally Responsible Architecture, Lima, Peru, 2012, pp. 1-6.

[15] S. Sarkar, Qualitative evaluation of comfort needs in urban walkways in major activity centers, Transportation Quarterly 57 (4) (2003) 39-59.

[16] Bauru, Secretaria Municipal de Cultura. Conselho de
Defesa do Patrimônio Cultural de Bauru, Bens Tombados (Municipal Culture. Defense Council of Bauru Cultural Heritage, Listed Buildings), Bauru, 2011. (in Portuguese)

[17] R.F.B. Salcedo, Recomendações para a salvaguarda do patrimônio arquitetônico e urbano nos centros históricos (Recommendations to safeguard the architectural and urban heritage in historic centers), in: M.S.G.C. Fontes, N.R.T. Constantino, L.C. Bittencourt (Organizers), Architecture and Urbanism: New Challenges for the XXI Century, Channel 6, Bauru, Brasil, 2009, pp. 69-82. (in Portuguese) 